\title{
Preliminary findings on the possible role of B-lymphocyte stimulator (BLyS) on diabetes-related periodontitis
}

\author{
Marx Haddley Ferreira \\ DRUMOND(a) \\ Luciano Eduardo PUHL(a) \\ Poliana Mendes DUARTE(b) iD \\ Tamires Szeremeske de \\ MIRANDA $^{(c)}$ \\ Juliana Trindade \\ CLEMENTE-NAPIMOGA(a) $^{(\mathrm{ID}}$ \\ Daiane Cristina PERUZZO(a) ID \\ Elizabeth Ferreira MARTINEZ(a) \\ Marcelo Henrique NAPIMOGA(a) \\ (a)Faculdade São Leopoldo Mandic, Instituto \\ de Pesquisas São Leopoldo Mandic, \\ Campinas, SP, Brazil. \\ (b) University of Florida, College of Dentistry, \\ Department of Periodontology, Gainesville, \\ FL, USA. \\ (c)Guarulhos University, Dental Research \\ Division, Department of Periodontology, São \\ Paulo, SP, Brazil.
}

Declaration of Interests: The authors certify that they have no commercial or associative interest that represents a conflict of interest in connection with the manuscript.

Corresponding Author: Marcelo Henrique Napimoga E-mail: marcelo.napimoga@gmail.com; marcelo.napimoga@sImandic.edu.br

https://doi.org/10.1590/1807-3107bor-2020.vol34.0038

Submitted: September 14, 2019

Accepted for publication: March 23, 2020

Last revision: March 27, 2020

\begin{abstract}
The possible role of B-cell growth and differentiationrelated cytokines on the pathogenesis of diabetes-related periodontitis has not been addressed so far. The aim of this study was to evaluate the effects of diabetes mellitus (DM) on the gene expression of proliferation-inducing ligand (APRIL) and B-lymphocyte stimulator (BLyS), two major cytokines associated to survival, differentiation and maturation of $\mathrm{B}$ cells in biopsies from gingival tissue with periodontitis. Gingival biopsies were obtained from subjects with periodontitis $(\mathrm{n}=17)$, with periodontitis and DM $(\mathrm{n}=19)$ as well as from periodontally and systemically healthy controls $(\mathrm{n}=10)$. Gene expressions for APRIL, BLyS, RANKL, OPG, TRAP and DC-STAMP were evaluated using qPCR. The expressions APRIL, BLyS, RANKL, OPG, TRAP and DC-STAMP were all higher in both periodontitis groups when compared to the control group $(p<0.05)$. Furthermore, the expressions of BLyS, TRAP and RANKL were significantly higher in the subjects with periodontitis and DM when compared to those with periodontitis alone $(p<0.05)$. The mRNA levels of BLyS correlated positively with RANKL in the subjects with periodontitis and DM $(p<0.05)$. BLyS is overexpressed in periodontitis tissues of subjects with type $2 \mathrm{DM}$, suggesting a possible role of this cytokine on the pathogenesis DM-related periodontitis.
\end{abstract}

Keywords: Periodontitis; Diabetes Mellitus; Inflammation; Cytokines.

\section{Introduction}

Periodontitis has long been linked to diabetes mellitus (DM) ${ }^{1,2}$ Nowadays, DM is considered a risk factor for periodontitis and has to be included as a descriptor in grading periodontitis based on the new clinical classification of periodontal diseases. ${ }^{3}$ The pathogenesis of DM is multifactorial, involving several metabolic and hemodynamic disorders like insulin resistance, dyslipidemia, hypertension, hyperglycemia and immune-inflammatory dysfunctions. The immune-inflammatory dysfunctions associated to DM include increase in reactive oxygen species and a shift to an overall pro-inflammatory profile. ${ }^{4,5}$

In recent years, the role of DM in modulating mediators involved in the pathogenesis of periodontal diseases has been studied by our research group. In brief, higher levels of pro-inflammatory T-helper (Th)1 - and 
Th17-cytokines have been reported in periodontitis from type 2 diabetic subjects when compared to non-diabetics. ${ }^{6,7,8,9}$ Furthermore, subjects with periodontitis and type $2 \mathrm{DM}$ exhibited elevated ratio of receptor activator of nuclear factor kappa-B ligand (RANKL)/osteoprotegerin (OPG), a key indicator of bone resorption, ${ }^{10}$ as well as increased expression of sclerostin and Dickkopf-1, important inhibitors of the Wnt/ $\beta$-catenin pathway and suppressors of bone formation. ${ }^{11}$ Moreover, increased expression of both peroxiredoxin II and superoxide dismutase II has been observed in sites with periodontitis in diabetic subjects, probably as a consequence of protective and adaptive mechanisms against increased levels of reactive oxidative species, as seen in a DM context. ${ }^{12}$

Although most studies have focused on the role of $\mathrm{T}$ cell-mediated immunity in the pathogenesis of periodontal diseases, pre-clinical and clinical studies have indicated a critical contribution of B cell to periodontal breakdown. B cell-deficient animals were protected from bacterial infection-induced alveolar bone loss. ${ }^{13,14}$ Furthermore, the number of multiple subsets of B and plasma cells exceeds the number of $\mathrm{T}$ cells in established periodontitis in human. ${ }^{15,16}$ A possible role of $B$ cells on osteoclastogenesis and alveolar bone loss during periodontitis has therefore been proposed. A previous study demonstrated that approximately $90 \%$ of B cells express RANKL in periodontitis lesions, whereas the percentage of RANKL-positive B cells in healthy gingiva is very low. ${ }^{17}$ Furthermore, there was a significant increase in B-cell RANKL expression in mice infected with Porphyromonas gingivalis. ${ }^{14}$ Moreover, memory B cells supported osteoclast differentiation in vitro in a RANKL-dependent manner, and B cells in the gingiva of animals submitted to experimental periodontitis produced RANKL and sustained osteoclastogenesis beyond $\mathrm{T}$ and other lymphocytes. ${ }^{18,19}$ Finally, B lineage cells were an important source of secreted osteoclastogenic factor of activated $\mathrm{T}$ cells (SOFAT) that induces bone resorption in a RANKLindependent manner in inflammatory states. ${ }^{20}$

Two major cytokines belonging to the tumor necrosis factor (TNF) superfamily, named proliferation-inducing ligand (APRIL; also identified as TNFSF13 or TALL-2) and B-lymphocyte stimulator
(BLyS; also identified as B cell-activating factor [BAFF], TNFSF13B, or TALL-1), have been proposed as essential factors to the survival, differentiation and maturation of B cells. ${ }^{21}$ Overexpression of BLyS and APRIL has been linked to development of several autoimmune diseases, such as systemic lupus erythematosus, Sjögren syndrome, immune thrombocytopenic purpura, rheumatoid arthritis and even neoplastic lesions. ${ }^{22}$ Previous studies demonstrated that subjects with periodontitis presented higher serum levels of APRIL and BLyS than periodontally-healthy subjects. ${ }^{23,24}$ In addition, the expression of APRIL and BLyS at mRNA and protein levels was locally higher in periodontitis in human and in experimental periodontitis in mice. ${ }^{25}$

Despite some evidence on the possible role of APRIL and BLyS on the pathogenesis of periodontitis, the impact of DM on this mechanism has seldom been explored. Therefore, the main aim of this study was to evaluate the effects of DM on BLyS and APRIL mRNA expression in gingival biopsies with periodontitis. The secondary aim was to correlate the expression of APRIL and BLyS with genes related to osteoclast formation and activity, including RANKL and OPG, markers of osteoclastogenesis, tartrate-resistant acid phosphatase (TRAP), an osteoclastic differentiation marker, and dendritic cell-specific transmembrane protein (DC-STAMP), an essential protein for cell fusion during osteoclastogenesis.

\section{Methodology}

Systemically healthy subjects without periodontitis (controls), systemically healthy subjects with periodontitis and type 2 diabetic subjects with periodontitis were sequentially selected from the population referred to the Periodontology Clinic of Guarulhos University (Guarulhos, Brazil) between March 2014 and September 2016. Qualified individuals were invited to participate in the study, fully informed of the nature, risks and benefits of the procedures and signed their informed consent. During volunteer screening, medical and dental histories were obtained. This study was approved by the Research Ethics Committee of the Guarulhos University (CAAE: 25526913.8.0000.5506). 
The inclusion criteria were individuals aged 30 years or older, presenting a minimum of 15 teeth, excluding third molars. Pregnant or breastfeeding women were excluded, as well as smokers and those with a history of subgingival periodontal therapy in the 6 months preceding the start of the study. Furthermore, individuals frequently using mouth rinses containing antimicrobials in the previous 2 months, systemic conditions other than DM that could influence the pathogenesis of periodontitis and the expression of the studied proteins [e.g. immunological disorders, bone-related diseases e complications (e.g., osteoporosis, ankylosing spondylitis, recent bone fractures, and rheumatoid arthritis)], use of antibiotics in the preceding 6 months, long-term use of anti-inflammatory, immunosuppressive (e.g., glucocorticoids) and antiresorptive agents (e.g., bisphosphonates and denosumab), hormone replacement therapy and orthodontic treatment were also excluded.

Inclusion criteria for subjects with periodontitis were as follow: generalized moderate or severe chronic periodontitis ${ }^{26}$ including $>30 \%$ of sites presenting probing depth (PD) and clinical attachment level $(\mathrm{CAL}) \geq 4 \mathrm{~mm}$ with bleeding on probing (BoP), $\geq 6$ teeth with $\geq 1$ sites with $P D$ and $C A L \geq 5 \mathrm{~mm}$ and $\mathrm{BoP}, \geq 1$ tooth indicated for extraction due to severe periodontitis. According to the new classification patients with generalized stage 3 or 4 , grade C. ${ }^{27}$ Subjects with no periodontitis should have had less than $10 \%$ positive marginal bleeding and/or BoP, no sites with both PD and CAL $>3 \mathrm{~mm}$ and at least one region needing crown lengthening. The diabetic subjects had to be formally diagnosed with type $2 \mathrm{DM}$ by a physician $(\mathrm{HbA1c}>6.5 \%$ and FPG $>99 \mathrm{mg} / \mathrm{dl}$ ) for at least 3 years prior to the start of the study. In order to attain expressive areas of periodontal inflammation, gingival biopsies were collected from a tooth referred for extraction due to severe periodontitis (PD and CAL $\geq 7 \mathrm{~mm}$, BoP, mobility and/or bone loss compromising more than $50 \%$ of the root) in the subjects with periodontitis.

\section{Clinical examinations}

Plaque index (PI), BoP, PD (mm), and CAL (mm) were evaluated at six sites per tooth, except third molars, by means of a manual periodontal probe (UNC15; Hu-Friedy, Chicago, USA) by the same examiner (TSM), who was trained and calibrated using a method described elsewhere. ${ }^{28}$

\section{Gingival tissue sampling}

In subjects with no periodontitis, the gingival biopsies were sampled from teeth without signs of clinical inflammation (BoP and/or MB), but requiring crown lengthening procedures. All samples included junctional and sulcular epithelia and connective gingival tissue. The gingival tissues were stored in TRIizol (Thermo Fisher Scientific, Waltham, MA) at $-80^{\circ} \mathrm{C}$ until RNA extraction.

\section{Gene expression}

The mRNA levels corresponding to BLyS, APRIL, RANKL, OPG, TRAP, DC-STAMP and glyceraldehyde-3-phosphate dehydrogenase (GAPDH) were assessed using Real Time PCR. The primer sequences are presented in Table 1 .

\section{RNA isolation}

Total RNA from the gingival biopsies was isolated using the Trizol method (Gibco BRL, Life Technologies, Rockville, USA), according to the manufacturer's

Table 1. Gene and primer sequence.

\begin{tabular}{|c|c|}
\hline Gene & Sequence \\
\hline \multirow{2}{*}{ BLyS } & F: AAC AGA CAG CCA CAG CCA AA \\
\hline & R: TGC CCC TTT GAA TTG TGT CCT \\
\hline \multirow{2}{*}{ APRIL } & F: AGC ACT CTG TCC TGC ACC T \\
\hline & R: CGG ACA CCA TAT CCT TGG GC \\
\hline \multirow{2}{*}{ RANKL } & 5' TACACGACTCAGTATCCATGC \\
\hline & 3’ AAGGTCAACCCGTAATTGC \\
\hline \multirow{2}{*}{ OPG } & 5' TCCGGAAACAGTGAATCAACTC \\
\hline & 3’ TCTCTGCGTTTACTTTGGTGC \\
\hline \multirow{2}{*}{ DC-STAMP } & F: TCC TCC ATG AAC AAA CAG TTC CAA \\
\hline & R: AGA CGT GGT TTA GGA ATG CAG CTC \\
\hline \multirow{2}{*}{ TRAP } & F: CCA GCG ACA AGA GGT TCC \\
\hline & R: AGA GAC GTT GCC AAG GTG AT \\
\hline \multirow{2}{*}{ GAPDH } & F: ACC CAC TCC TCC ACC TTT GA \\
\hline & R: TGT TGC TGT AGC CAA ATT CGT T \\
\hline
\end{tabular}

F: Foward; R: Reverse; Demographic characteristics, glycaemic and periodontal parameters (mean $\pm \mathrm{SD}$ ); FM: full-mouth, BoP: bleeding on probing, PD: probing depth, CAL: clinical attachment level. Different letters indicate differences among groups. 
recommendation. RNA samples were re-suspended in diethylpyrocarbonate-treated water and stored at $-80^{\circ} \mathrm{C}$. RNA concentration was established based on optical density using a micro-volume spectrophotometer (Nanodrop 1000, Nanodrop Technologies LLC, Wilmington, USA).

\section{Reverse transcription}

Total RNA was treated with DNase (Turbo DNA-frees, Ambion Inc., USA). Subsequently, $1 \mu \mathrm{g}$ of DNase-treated RNA was used for complementary DNA (cDNA) synthesis. This reaction was performed using the First- Strand cDNA synthesis kit (Roche Diagnostic Co., USA), following the manufacturer's recommendations.

\section{Quantitative real-time polymerase chain reaction (qPCR)}

The qPCR reactions were done in the 7300 Real Time PCR (Applied Biosystem), using the SYBR Green PCR Master Mix (Thermo Fisher Scientific, Waltham, USA), according to the manufacturer's recommendations. The reaction products were calculated using the Relative Quantification tool, based on GAPDH as the reference gene. Negative controls with SYBR Green PCR Master Mix and water were used for all reactions.

\section{Statistical analysis}

As no previous study comparing the gene expression of BLyS and APRIL in tissues with periodontitis in diabetic and non-diabetic patients to perform a sample power calculation, a post hoc analysis was performed to establish it. Considering differences of at least 1.1 in mRNA levels of BLyS between tissues with periodontitis of diabetic and non-diabetic subjects, and a standard deviation of 0.88 , it was estimated that 9 subjects per group would be necessary to provide $85 \%$ power with an alpha of 0.05 . The statistical analyses were performed on GraphPad Prism 6.0 (La Jolla, USA). Data were first examined for normality using the Kolmogorov-Smirnov test. Non-parametric methods were used for data that did not conform to the assumptions of normality. The mean percentages of sites with visible plaque accumulation, BoP, mean PD and CAL were computed for all teeth. Subsequently, the clinical parameters at full-mouth and sampled tooth levels as well as mRNA expression were averaged for each group. The differences among groups regarding clinical parameters, age and mRNA levels were compared using the Kruskal-Wallis and Dunn tests. Spearman's correlation was used for bivariate correlations between the expressions of the biomarkers studied. The significance level for all analyses was established at $5 \%$.

\section{Results}

The intra-examiner variability (standard error of measurement) was $0.23 \mathrm{~mm}$ for PD and $0.24 \mathrm{~mm}$ for CAL. The concordance for BoP was $93 \%$ by Kappa-light test.

Table 2. Demographic characteristics, glycaemic and periodontal parameters (mean \pm SD).

\begin{tabular}{lccc}
\hline Variable & Healthy & Periodontitis & Periodontitis + DM \\
\hline Gender (M/F) & $2 / 8$ & $5 / 12$ & $6 / 13$ \\
Age (years) & $34.6 \pm 4.6 a$ & $50.0 \pm 10.1 \mathrm{~b}$ & $56.6 \pm 9.3 \mathrm{~b}$ \\
Years of DM & 0 & 0 & $6.3 \pm 5.3$ \\
HbAlc & $6.0 \pm 0.2 \mathrm{a}$ & $5.8 \pm 0.2 \mathrm{a}$ & $7.8 \pm 1.2 \mathrm{~b}$ \\
FM \% of sites with plaque & $11.1 \pm 3.6 \mathrm{a}$ & $59.3 \pm 24.5 \mathrm{~b}$ & $73.8 \pm 23.5 \mathrm{~b}$ \\
FM \% of sites with BoP & $9.0 \pm 3.3 \mathrm{a}$ & $47.3 \pm 15.2 \mathrm{~b}$ & $40.4 \pm 10.9 \mathrm{~b}$ \\
FM PD (mm) & $1.7 \pm 0.1 \mathrm{a}$ & $3.3 \pm 0.9 \mathrm{~b}$ & $3.7 \pm 0.8 \mathrm{~b}$ \\
FM CAL (mm) & $0.7 \pm 0.9 \mathrm{a}$ & $4.3 \pm 0.9 \mathrm{~b}$ & $5.0 \pm 1.0 \mathrm{~b}$ \\
Sampled teeth PD (mm) & $2.6 \pm 0.7 \mathrm{a}$ & $5.0 \pm 1.6 \mathrm{~b}$ & $5.7 \pm 1.2 \mathrm{~b}$ \\
Sampled teeth CAL (mm) & $0.8 \pm 1.0 \mathrm{a}$ & $7.9 \pm 2.2 \mathrm{~b}$ & $7.4 \pm 1.8 \mathrm{~b}$ \\
\hline
\end{tabular}

FM: full-mouth, BoP: bleeding on probing, PD: probing depth, CAL: clinical attachment level; Different lefters indicate differences among groups 
Gingival biopsies were collected from ten systemically healthy subjects without periodontitis, 17 systemically healthy subjects with periodontitis and 19 type-2 diabetic subjects, selected from almost 130 subjects screened. No samples were lost during laboratorial preparation.

Table 2 presents the demographic characteristics of the study population and the clinical parameters considering the sampled teeth and full-mouth levels. All clinical parameters were significantly lower in the control group, when compared to both periodontitis groups ( $\mathrm{p}<0.05$, Table 2$)$.

Figure presents the gene expression of BLyS, APRIL, RANKL, OPG, TRAP and DC-STAMP relative to GAPDH. The expressions of BLyS (Figure A), APRIL (Figure B), RANKL (Figure C), OPG (Figure D), RANKL/OPG (Figure E), TRAP (Figure F) and DC-STAMP (Figure G) were all significantly higher in both groups with periodontitis, when compared to the control $(\mathrm{p}<0.05)$. In addition, individuals with periodontitis and DM exhibited higher BLyS, RANKL and TRAP expressions than the group with periodontitis alone $(\mathrm{p}<0.05)$. APRIL, OPG, RANKL/OPG and DC-STAMP expression did not differ between periodontitis groups with or without $\mathrm{DM}(\mathrm{p}>0.05)$.

Table 3 presents the correlation coefficients between the expression of the biomarkers studied. In the control group, APRIL mRNA levels showed positive correlations with DC-STAMP and RANKL $(\mathrm{p}<0.05)$. Moreover, the mRNA levels of DC-STAMP positively correlated with RANKL ( $\mathrm{p}<0.05)$. BLyS positively correlated with APRIL while TRAP positively correlated with RANKL in subjects with periodontitis alone and in subjects with periodontitis and DM $(p<0.05)$. Furthermore, the mRNA levels of BLyS correlated positively with RANKL in the subjects with periodontitis and DM $(p<0.05)$.

\section{Discussion}

This study is the first to assess the gene expression of BLyS and APRIL, two major cytokines that support $B$ cells differentiation and proliferation in DM-related periodontitis, and to correlate their expression with those of osteoclast differentiation and activity markers.
The main results demonstrated an overall higher expression of both BLyS and APRIL in gingival tissues from subjects with periodontitis when compared to those from subjects without periodontitis. Most importantly, significantly higher expression of BLyS was observed in gingival biopsies from patients presenting with periodontitis and DM when compared to those from subjects with periodontitis alone. Furthermore, BLyS correlated positively with RANKL in subjects with periodontitis and DM. These findings suggest a possible involvement of BLyS in the pathogenesis of DM-related periodontitis.

In the current study, BLyS and APRIL expression were upregulated in gingival tissues of subjects with periodontitis when compared to those with no periodontitis. In support of these findings, previous investigations have demonstrated elevated salivary and serum levels of BLyS and APRIL in individuals with periodontitis when compared to periodontally healthy subjects. ${ }^{23,24}$ Furthermore, the gingival expression of APRIL and BLyS at mRNA and protein levels were upregulated in natural and experimental periodontitis in humans and mice, respectively, when compared to healthy controls ${ }^{25}$. Altogether, these findings support the roles of both APRIL and BLyS in the pathogenesis of the periodontal diseases, possibly fostering the expansion and maintenance of the B cells, found in high proportions in periodontitis lesions.

In this study, gingival tissues with periodontitis also exhibited higher expression of RANKL, OPG, TRAP and DC-STAMP than periodontally healthy tissues. RANKL-RANK signaling regulates osteoclast differentiation, activation, and survival during physiological and pathological conditions. OPG protects excessive bone resorption by binding RANKL and preventing it from binding RANK. ${ }^{29}$ Therefore, in line with the findings from the present study, an increased RANKL/OPG ratio has been found in subjects with periodontitis. ${ }^{30,31}$ TRAP is a member of the ubiquitously expressed enzyme family of the acid phosphatases that prompts dephosphorylation of bone matrix phosphoproteins like osteopontin and bone sialoprotein, ${ }^{32}$ being a recognized cytochemical marker of osteoclasts. ${ }^{33}$ DC-STAMP is an important protein currently considered as a master regulator of the cell fusion step of osteoclastogenesis. ${ }^{34,35}$ 

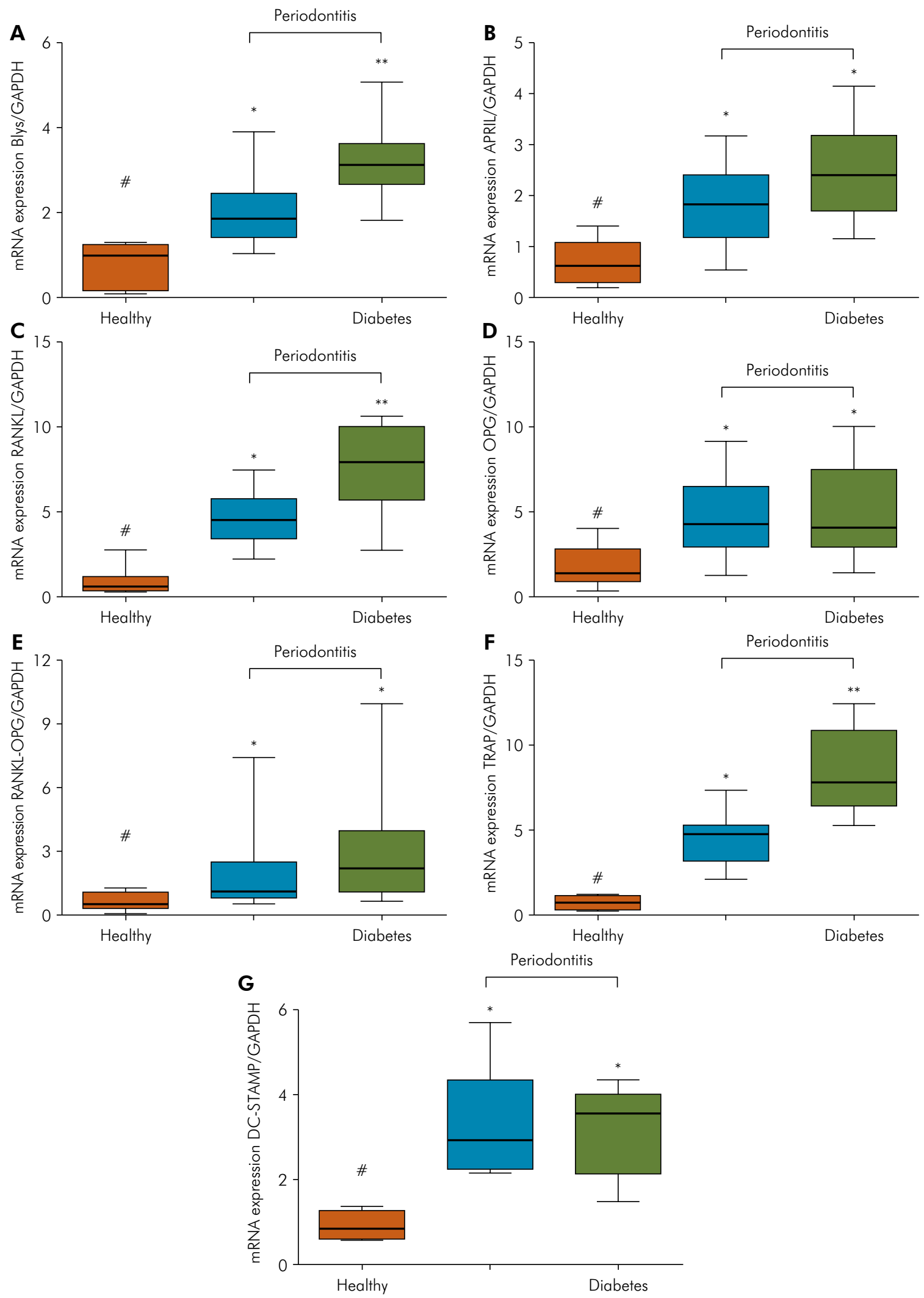

Figure. Relative expression of genes. qPCR analysis of BLyS (A), APRIL (B), RANKL (C), OPG (D), RANKL/OPG (E), TRAP (F) and DC-STAMP $(G)$ expression on mRNA extracted from gingival tissue of healthy and periodontitis patients, associated or not with diabetes mellitus (DM). Different symbols indicate statistical significance amongst the groups $(p<0.05)$. 
Table 3. Correlation coefficients among all biomarkers at mRNA levels.

\begin{tabular}{lcccccc}
\hline Variable & BLYS & APRIL & RANKL & OPG & TRAP & DC-STAMP \\
\hline Control & & & & & & \\
BLYS & 1.00 & -0.36 & 0.25 & -0.47 & -0.06 & 0.40 \\
APRIL & - & 1.00 & $0.82^{*}$ & 0.66 & 0.05 & $0.97^{*}$ \\
RANKL & - & - & 1.00 & 0.36 & 0.03 & $0.98^{*}$ \\
OPG & - & - & - & 1.00 & -0.08 & 0.77 \\
TRAP & - & - & - & - & 1.00 & -0.07 \\
DC-STAMP & - & - & - & - & - & 1.00 \\
Periodontitis & & & & & & \\
BLYS & 1.00 & $0.70^{*}$ & 0.22 & 0.03 & 0.10 & 0.22 \\
APRIL & - & 1.00 & 0.26 & -0.11 & 0.02 & 0.09 \\
RANKL & - & - & 1.00 & 0.25 & $0.80^{*}$ & 0.41 \\
OPG & - & - & - & 1.00 & 0.01 & -0.25 \\
TRAP & - & - & - & - & 1.00 & 0.06 \\
DC-STAMP & - & - & - & - & - & 1.00 \\
Periodontitis/DM & & & & & & 0.45 \\
BLYS & 1.00 & $0.75^{*}$ & $0.51^{*}$ & -0.01 & 0.47 & 0.45 \\
APRIL & - & 1.00 & 0.32 & -0.02 & 0.30 & 0.91 \\
RANKL & - & - & 1.00 & 0.22 & $0.72^{*}$ & 0.59 \\
OPG & - & - & - & 1.00 & -0.46 & -0.51 \\
TRAP & - & - & - & - & 1.00 & -0.25 \\
DC-STAMP & - & - & - & - & - & 1.00 \\
\hline
\end{tabular}

DC-STAMP-knockout mice presented significantly lower bone resorption in a ligature-induced periodontitis model compared to wild type mice, while local administration of anti-DC-STAMP-mAb downregulated the ligature-induced bone loss and the number of multinucleated TRAP+ cells, by downregulating cell fusion of osteoclasts precursors cells in mice. ${ }^{36,37}$ Overexpression of the genes involved in the multiple steps leading to osteoclastogenesis observed in the tissues with periodontitis were therefore expected findings, which support the bone resorption process during the pathogenesis of periodontitis.

The most unique finding of the current study is that the expression of BLyS was higher in subjects with periodontitis and DM than in subjects with periodontitis alone, while these groups did not differ significantly in terms of APRIL expression. The role of BLyS and APRIL have been well documented in the context of B cells, as both cytokines are described as key regulators of survival and/or expansion of B-cell subsets. ${ }^{38}$ However, a previous study from our group demonstrated a tendency toward low levels of B plasma cells in gingival tissues with periodontitis from type 2 diabetic subjects, when compared to those from subjects without DM.7 It is important to point out that BLyS and APRIL exert their functions by interacting with their receptors (BAFF-R), the transmembrane activator and cyclophilin ligand interactor (TACI) and the B-cell maturation antigen (BCMA), which are expressed not only in B-cell subsets but also in different types of immune cells including monocytes, dendritic cells and T cells. Therefore, evidence has shown that BLyS and APRIL are also related to T-cell differentiation and maintenance and to the production of proinflammatory cytokines. ${ }^{22,39,40}$ BLyS is particularly recognized as a significant co-stimulator of T-cell function, besides regulating multiple B-cell-related functions. Human T cells secrete pro-inflammatory cytokines, such as interferon (IFN)- $\gamma$ and interleukin (IL)-2, under the stimulation of recombinant or endogenous BLyS. ${ }^{41,42} \mathrm{BLyS}$ is also a critical cytokine for the development of glucose intolerance. ${ }^{43}$ 
Noteworthy, besides the expression of BLyS, RANKL and TRAP were also overexpressed in patients with periodontitis and DM, when compared to those with periodontitis alone. Furthermore, the expression of BLyS correlated positively with the expression of RANKL in the diabetic subjects with periodontitis.

Previous study demonstrated that $\sim 50 \%$ of $\mathrm{T}$ cells and $\sim 90 \%$ of B cells in tissues with periodontitis express RANKL. ${ }^{17,19}$ Despite the evidence suggesting that B cells express more RANKL and support more osteoclastogenesis than $\mathrm{T}$ in periodontitis, ${ }^{17,19}$ further studies are needed to elucidate the influence of DM on the interaction among BLyS, B cells, T cells and RANKL expression. Our preliminary data are just able to suggest that increased expression of BLyS, RANKL and TRAP in tissues of type 2 diabetic subjects might contribute to the pathogenesis of periodontitis in these subjects. However, whether $B$ cells and/or T cells are activated and maintained with increased BLyS expression under DM challenge needs further investigation.

The main strength of this study is to show for the first time a possible role of BLys on the pathogenesis of DM-related periodontitis. The small sample size, particularly in the control group, was anticipated to be a limitation of the present study; however, all genes studied differed in expression between control and periodontitis groups with statistical significance. Another limitation of this study was the lack of a group of patients with diabetes but without periodontitis. This group should be included in further studies in order to determine the influence of DM only on the expression of the studied molecules. Determining which cells are essential BLyS targets and whether, and to what extent, this cytokine really confer greater susceptibility to periodontal breakdown in diabetic patients require significant further investigation.

In conclusion, BLyS is overexpressed in periodontitis tissues of subjects with type $2 \mathrm{DM}$, which may be critical to the pathogenesis DM-related periodontitis.

\section{Acknowledgment}

This work was supported by Conselho Nacional de Desenvolvimento Científico e Tecnológico (CNPq) - Research Productivity Fellowships were awarded to MHN, EFM and JTCN and Coordenação de Aperfeiçoamento de Pessoal de Nível Superior (CAPES) for provide full access of the manuscripts.

\section{References}

1. Löe H. Periodontal disease. The sixth complication of diabetes mellitus. Diabetes Care. 1993 Jan;16(1):329-34. https://doi.org/10.2337/diacare.16.1.329

2. Demmer RT, Holtfreter B, Desvarieux M, Jacobs DR Jr, Kerner W, Nauck M, et al. The influence of type 1 and type 2 diabetes on periodontal disease progression: prospective results from the Study of Health in Pomerania (SHIP). Diabetes Care. 2012 Oct;35(10):2036-42. https://doi.org/10.2337/dc11-2453

3. Caton JG, Armitage G, Berglundh T, Chapple IL, Jepsen S, Kornman KS, et al. A new classification scheme for periodontal and peri-implant diseases and conditions - Introduction and key changes from the 1999 classification. J Periodontol. 2018 Jun;89 Suppl 1:S1-8. https://doi.org/10.1002/JPER.18-0157

4. Forbes JM, Cooper ME. Mechanisms of diabetic complications. Physiol Rev. 2013 Jan;93(1):137-88. https://doi.org/10.1152/physrev.00045.2011

5. Verhulst MJ, Loos BG, Gerdes VE, Teeuw WJ. Evaluating all potential oral complications of diabetes mellitus. Front Endocrinol (Lausanne). 2019 Feb;10:56. https://doi.org/10.3389/fendo.2019.00056

6. Santos VR, Ribeiro FV, Lima JA, Napimoga MH, Bastos MF, Duarte PM. Cytokine levels in sites of chronic periodontitis of poorly controlled and well-controlled type 2 diabetic subjects. J Clin Periodontol. 2010 Dec;37(12):1049-58. https://doi.org/10.1111/j.1600-051X.2010.01624.x

7. Duarte PM, Santos VR, Santos FA, Pereira SAL, Rodrigues DB, Napimoga MH. Role of smoking and type 2 diabetes in the immunobalance of advanced chronic periodontitis. J Periodontol. 2011 Mar;82(3):429-38. https://doi.org/10.1902/jop.2010.100215

8. Duarte PM, Bezerra JP, Miranda TS, Feres M, Chambrone L, Shaddox LM. Local levels of inflammatory mediators in uncontrolled type 2 diabetic subjects with chronic periodontitis. J Clin Periodontol. 2014 Jan;41(1):11-8. https://doi.org/10.1111/icpe.12179

9. Franco MM, Moraes MM, Duarte PM, Napimoga MH, Benatti BB. Glycemic control and the production of cytokines in diabetic patients with chronic periodontal disease. RGO Rev Gaúch Odontol. 2015;63(4):432-8. https://doi.org/10.1590/1981-863720150003000093063. 
10. Ribeiro FV, Mendonça AC, Santos VR, Bastos MF, Figueiredo LC, Duarte PM. Cytokines and bone-related factors in systemically healthy patients with chronic periodontitis and patients with type 2 diabetes and chronic periodontitis. J Periodontol. 2011 Aug;82(8):1187-96. https://doi.org/10.1902/jop.2011.100643

11. Miranda TS, Napimoga MH, Feres M, Marins LM, Cruz DF, Silva HD, et al. Antagonists of Wnt/ $\beta$-catenin signalling in the periodontitis associated with type 2 diabetes and smoking. J Clin Periodontol. 2018 Mar;45(3):293-302. https://doi.org/10.1111/icpe.12854

12. Duarte PM, Napimoga MH, Fagnani EC, Santos VR, Bastos MF, Ribeiro FV, et al. The expression of antioxidant enzymes in the gingivae of type 2 diabetics with chronic periodontitis. Arch Oral Biol. 2012 Feb;57(2):161-8. https://doi.org/10.1016/j.archoralbio.2011.08.007

13. Baker PJ, Boutaugh NR, Tiffany M, Roopenian DC. B Cell IgD deletion prevents alveolar bone loss following murine oral infection. Interdiscip Perspect Infect Dis. 2009;2009:864359. https://doi.org/10.1155/2009/864359

14. Oliver-Bell J, Butcher JP, Malcolm J, MacLeod MK, Planell AA, Campbell L, et al. Periodontitis in the absence of B cells and specific anti-bacterial antibody. Mol Oral Microbiol. 2015 Apr;30(2):160-9. https://doi.org/10.1111/omi.12082

15. Thorbert-Mros S, Larsson L, Berglundh T. Cellular composition of long-standing gingivitis and periodontitis lesions. J Periodontal Res. 2015 Aug;50(4):535-43. https://doi.org/10.1111/ire.12236

16. Mahanonda R, Champaiboon C, Subbalekha K, Sa-Ard-lam N, Rattanathammatada W, Thawanaphong S, et al. Human Memory B Cells in Healthy Gingiva, Gingivitis, and Periodontitis. J Immunol. 2016 Aug;197(3):715-25. https://doi.org/10.4049/jimmunol.1600540

17. Kawai T, Matsuyama T, Hosokawa Y, Makihira S, Seki M, Karimbux NY, et al. B and T lymphocytes are the primary sources of RANKL in the bone resorptive lesion of periodontal disease. Am J Pathol. 2006 Sep;169(3):987-98. https://doi.org/10.2353/ajpath.2006.060180

18. Han YK, Jin Y, Miao YB, Shi T, Lin XP. Improved RANKL production by memory B cells: A way for B cells promote alveolar bone destruction during periodontitis. Int Immunopharmacol. 2018 Nov;64:232-7. https://doi.org/10.1016/i.intimp.2018.08.033

19. Han Y, Jin Y, Miao Y, Shi T, Lin X. Improved RANKL expression and osteoclastogenesis induction of CD27+CD38- memory B cells: a link between B cells and alveolar bone damage in periodontitis. J Periodontal Res. 2019 Feb;54(1):73-80. https://doi.org/10.1111/ire.12606

20. Jarry CR, Martinez EF, Peruzzo DC, Carregaro V, Sacramento LA, Araújo VC, et al. Expression of SOFAT by T- and B-lineage cells may contribute to bone loss. Mol Med Rep. 2016 May;13(5):4252-8. https://doi.org/10.3892/mmr.2016.5045

21. Mackay F, Schneider P, Rennert P, Browning J. BAFF AND APRIL: a tutorial on B cell survival. Annu Rev Immunol. 2003;21(1):231-64. https://doi.org/10.1146/annurev.immunol.21.120601.141152

22. Shabgah AG, Shariati-Sarabi Z, Tavakkol-Afshari J, Mohammadi M. The role of BAFF and APRIL in rheumatoid arthritis. J Cell Physiol. 2019 Aug;234(10):17050-63. https://doi.org/10.1002/jcp.28445

23. Nile CJ, Sherrabeh S, Ramage G, Lappin DF. Comparison of circulating tumour necrosis factor superfamily cytokines in periodontitis patients undergoing supportive therapy: a case-controlled cross-sectional study comparing smokers and non-smokers in health and disease. J Clin Periodontol. 2013 Sep;40(9):875-82. https://doi.org/10.1111/jcpe.12134

24. Gümüş P, Nizam N, Lappin DF, Buduneli N. Saliva and serum levels of B-cell activating factors and tumor necrosis factor- $\alpha$ in patients with periodontitis. J Periodontol. 2014 Feb;85(2):270-80. https://doi.org/10.1902/jop.2013.130117

25. Abe T, AISarhan M, Benakanakere MR, Maekawa T, Kinane DF, Cancro MP, et al. The B cell-stimulatory cytokines BLyS and APRIL are elevated in human periodontitis and are required for B cell-dependent bone loss in experimental murine periodontitis. J Immunol. 2015 Aug;195(4):1427-35. https://doi.org/10.4049/jimmunol.1500496

26. Armitage GC. Development of a classification system for periodontal diseases and conditions. Ann Periodontol. 1999 Dec;4(1):1-6. https://doi.org/ 10.1902/annals.1999.4.1.1

27. Papapanou PN, Sanz M, Buduneli N, Dietrich T, Feres M, Fine DH, et al. Periodontitis: Consensus report of workgroup 2 of the 2017 World Workshop on the Classification of Periodontal and Peri-Implant Diseases and Conditions. J Periodontol. 2018 Jun;89 Suppl 1:S173-S182. https://doi.org/10.1002/JPER.17-0721

28. Araujo MW, Hovey KM, Benedek JR, Grossi SG, Dorn J, Wactawski-Wende J, et al. Reproducibility of probing depth measurement using a constant-force electronic probe: analysis of inter- and intraexaminer variability. J Periodontol. 2003 Dec;74(12):1736-40. https://doi.org/10.1902/jop.2003.74.12.1736

29. Boyce BF, Xing L. Biology of RANK, RANKL, and osteoprotegerin. Arthritis Res Ther. 2007;9 Suppl 1:S1. https://doi.org/10.1186/ar2165

30. Belibasakis GN, Bostanci N. The RANKL-OPG system in clinical periodontology. J Clin Periodontol. 2012 Mar;39(3):239-48. https://doi.org/10.1111/i.1600-051X.2011.01810.x

31. Balli U, Aydogdu A, Dede FO, Turer CC, Guven B. Gingival crevicular fluid levels of sclerostin, osteoprotegerin, and receptor activator of nuclear factor-KB ligand in periodontitis. J Periodontol. 2015 Dec;86(12):1396-404. https://doi.org/10.1902/jop.2015.150270

32. Hayman AR. Tartrate-resistant acid phosphatase (TRAP) and the osteoclast/immune cell dichotomy. Autoimmunity. 2008 Apr;41(3):218-23. https://doi.org/10.1080/08916930701694667

33. Lamp EC, Drexler HG. Biology of tartrate-resistant acid phosphatase. Leuk Lymphoma. 2000 Nov;39(5-6):477-84. https://doi.org/10.3109/10428190009113378

34. Chiu YH, Ritchlin CT. DC-STAMP: a key regulator in osteoclast differentiation. J Cell Physiol. 2016 Nov;231(11):2402-7. https://doi.org/10.1002/icp.25389 
- Preliminary findings on the possible role of B-lymphocyte stimulator (BLyS) on diabetes-related periodontitis

35. Witwicka H, Hwang SY, Reyes-Gutierrez P, Jia H, Odgren PE, Donahue LR, et al. Studies of OC-STAMP in osteoclast fusion: a new knockout mouse model, rescue of cell fusion, and transmembrane topology. PLoS One. 2015 Jun;10(6):e0128275. https://doi.org/10.1371/journal.pone.0128275

36. Wisitrasameewong W, Kajiya M, Movila A, Rittling S, Ishii T, Suzuki M, et al. DC-STAMP is an osteoclast fusogen engaged in periodontal bone resorption. J Dent Res. 2017 Jun;96(6):685-93. https://doi.org/10.1177/0022034517690490

37. Ishii T, Ruiz-Torruella M, Ikeda A, Shindo S, Movila A, Mawardi H, et al. OC-STAMP promotes osteoclast fusion for pathogenic bone resorption in periodontitis via up-regulation of permissive fusogen CD9. FASEB J. 2018 Jul;32(7):4016-30. https://doi.org/10.1096/fj.201701424R

38. Woodland RT, Schmidt MR, Thompson CB. BLyS and B cell homeostasis. Semin Immunol. 2006 Oct;18(5):318-26. https://doi.org/10.1016/i.smim.2006.06.001

39. Stein JV, López-Fraga M, Elustondo FA, Carvalho-Pinto CE, Rodríguez D, Gómez-Caro R, et al. APRIL modulates B and T cell immunity. J Clin Invest. 2002 Jun;109(12):1587-98. https://doi.org/10.1172/JCl0215034

40. Salazar-Camarena DC, Ortíz-Lazareno P, Marín-Rosales M, Cruz A, Muñoz-Valle F, Tapia-Llanos R, et al. BAFF-R and TACl expression on CD3+ T cells: interplay among BAFF, APRIL and T helper cytokines profile in systemic lupus erythematosus. Cytokine. 2019 Feb;114:115-27. https://doi.org/10.1016/i.cyto.2018.11.008

41. Yu G, Boone T, Delaney J, Hawkins N, Kelley M, Ramakrishnan M, et al. APRIL and TALL-I and receptors BCMA and TACI: system for regulating humoral immunity. Nat Immunol. 2000 Sep;1(3):252-6. https://doi.org/10.1038/79802

42. Schneider P. The role of APRIL and BAFF in lymphocyte activation. Curr Opin Immunol. 2005 Jun;17(3):282-9. https://doi.org/10.1016/i.coi.2005.04.005

43. Kim B, Do MS, Hyun CK. B-cell-activating factor deficiency attenuates high-fat diet-induced glucose intolerance by potentiating adipose tissue function. Biochem Biophys Res Commun. 2015 Sep;464(4):1171-7. https://doi.org/10.1016/i.bbrc.2015.07.099 